\title{
Análise da variação pluviométrica no município de Santa Inês - BA
}

\author{
Analysis of rainfall variation in the municipality of Santa Inês - BA
}

\author{
NUNES ${ }^{1}$, F. C.; CARVALHO ${ }^{2}$, C. C. N.; MOREIRA, G. S.; SANTOS, M. A. S.; SANTOS, T. J. \\ fabio.nunes@si.ifbaiano.edu.br
}

\begin{abstract}
Resumo
O trabalho teve o objetivo de investigar a variabilidade climática no município de Santa Inês nos anos de 2011 e 2012, suas causas e efeitos na precipitação. Os estudos foram realizados a partir de levantamentos de dados primários na estação pluviométrica de Santa Inês e correlacionados com a dinâmica atmosférica em macro e mesoescalas, através de análises dos boletins quinzenais e mensais do INMET. Os resultados mostram que no ano de 2011 a precipitação anual esteve $90,5 \mathrm{~mm}$ abaixo das normais climatológicas, contudo no período historicamente úmido as chuvas foram superiores à média. O desvio negativo, por conseguinte, se deu nos meses secos, o que agravou os problemas relacionados à seca. O ano de 2012 foi mais seco que o de 2011, apresentando índices pluviométricos de regiões consideradas desérticas. As precipitações de 2012 apresentaram um desvio negativo de $337,4 \mathrm{~mm}$ e a diminuição dos totais ocorreu em praticamente todos os meses do ano, exceto em agosto. Embora a fase fria do fenômeno Enos-Oscilação Sul estivesse ativa em vários dos meses analisados, fenômenos oceano-atmosféricos, como as águas superficiais mais frias que o normal no Atlântico Tropical Sul contribuíram para a escassez de chuvas no semiárido nordestino e em Santa Inês.
\end{abstract}

Palavras-chave: clima, variabilidade climática, sistemas meteorológicos.

\begin{abstract}
The study had as objectives to investigate the climatic variability, and its causes and effects on precipitation at Santa Inês city at the years 2011 and 2012. The analyses was realized based on primary data surveys from the pluviometric station of Santa Inês, and correlated to the atmosphere dynamics in macro and mesoscales. The correlation was made by means of the analyses of fortnight and monthly bulletins from INMET. The results reveal for the year of 2011 the annual precipitation was $90.5 \mathrm{~mm}$ under the normal climatic conditions, however in the historical humid period the rains were above average. The negative deviation, thus, happened during the dry months, what made more severe the drought problems. The year of 2012 was dryer than 2011, showing pluviometric levels of desert areas. This year precipitations deviated $337.4 \mathrm{~mm}$ negatively, and the decrease from the total occurred in all months, besides august. Although the cold phase of the Enos Southern Oscillation was active during the analyzed months of study, ocean/atmospheric phenomena, as the superficial waters being colder than normal for the South Tropical Atlantic contributed to the rains scarcity in the Brazilian northeast semiarid and in Santa Inês
\end{abstract}

Keywords: climate, climatic variability, meteorological systems.

\section{INTRODUÇÃO}

O clima pode ser entendido como "a sucessão habitual dos vários tipos de tempo" (SORRE, 1951). Contudo, é preciso esclarecer que as condições climáticas variam ao longo do tempo, podendo produzir importantes modificações no hábito ou ritmo dos "tipos de tempo" que se espera, por exemplo, em uma década ou em determinados anos. A variabilidade climática pode ser entendida como capacidade do sistema atmosférico terrestre em produzir oscilações naturais, as quais podem ser observadas em diferentes escalas, da local a global. As variabilidades ou flutuações do clima são capazes de produzir impactos importantes na produção agrícola, pecuária e na saúde humana, especialmente naqueles espaços onde a infraestrutura é inadequada e as condições socioeconômicas são mais precárias. 
Vários fatores diretos e indiretos estão relacionados à variabilidade climática, dentre eles as alterações da Temperatura Superficial do Mar (TSM) do Oceano Pacífico Equatorial e do Oceano Atlântico Tropical, a Oscilação Decadal do Pacífico (ODP) (MANTUA et al., 1997) e o fenômeno El Niño - Oscilação Sul. Estes eventos afetam a circulação atmosférica e acabam produzindo anomalias nos padrões de precipitação e temperatura local, regional e global.

Devido à importância para a sociedade civil dos impactos provocados pela variação do clima, investigaram-se as causas e os efeitos da variabilidade climática na precipitação do município de Santa Inês - Bahia nos anos de 2011 e 2012. O município está localizado no Território de Identidade do Vale do Rio Jequiriçá, onde os índices socioeconômicos são baixos e as condições de infraestrutura são pouco adequadas, por isso bastante vulnerável aos impactos negativos provados pela variabilidade climática.

\section{METODOLOGIA}

Os estudos foram realizados a partir de levantamentos de dados pluviométricos na estação de Santa Inês, município de Santa Inês - BA, unidade gerida pela Companhia de Pesquisa Mineral (CPRM), situada a $481 \mathrm{~m}$ de altitude, coordenadas $13^{\circ} 16^{\prime} \mathrm{S}$ e $39^{\circ} 48^{\prime} \mathrm{W}$. A área de estudo compõe o Território de Identidade Vale do Jequiriçá e está localizada no semiárido, na Macrorregião Pluviométrica V do Estado da Bahia (INGÁ/CEMBA, 2009). A escala temporal escolhida para a pesquisa foi 2011 e 2012, pois a região foi afetada por uma forte seca em anos que se esperava o oposto, porque a La Ninã estava ativa na maioria dos meses.

Os fenômenos oceano-atmosféricos atuantes nos anos de 2011 e 2012 foram identificados através dos boletins quinzenais e mensais do INMET, a fim de correlacioná-los com as precipitações e sua escassez no semiárido e em Santa Inês.

Os dados coletados na estação de Santa Inês, as correlações e inferências realizadas através dos boletins do INMET tiveram como principal objetivo investigar as causas da variabilidade climática no município de Santa Inês no período supracitado e os efeitos na precipitação.

\section{RESULTADOS E DISCUSSÃO}

Sistemas Meteorológicos e Normais Climatológicas

$\mathrm{Na}$ área de estudo os principais fenômenos meteorológicos são provocados pela Zona de Convergência Intertropical (ZCIT), pelos Sistemas Frontais (SF), pelos Vórtices Ciclônicos de Ar Superior (VCAS) e pela Zona de Convergência do Atlântico Sul (ZCAS) (INGÁ/CEMBA, 2009). Contudo, a Zona de Convergência Intertropical (ZCIT) é o principal sistema meteorológico 
provocador das chuvas em Santa Inês, especialmente na primavera-verão, e os Sistemas Frontais (SF) são responsáveis pela diminuição das médias térmicas anuais (Figura 01).

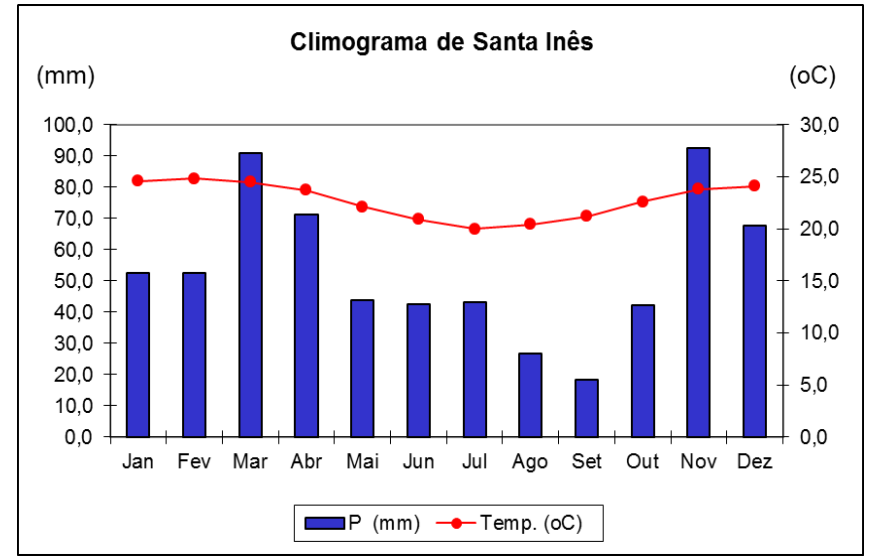

Figura 01. Normais climatológicas de Santa Inês - Bahia. Estação: Santa Inês. Período: 1946-1976. Altitude: 481m. Latitude: $13^{\circ} 16^{\prime} \mathrm{S}$. Longitude: $39^{\circ} 48^{\prime} \mathrm{W}$.

O clima da área é BSh na classificação de Koppen e DdB'4a' (semiárido), segundo Thornthwaite e Mather. A precipitação média anual é de $643,6 \mathrm{~mm}$, com déficit hídrico em todos os meses do ano e índice de aridez entre 13 e 75\%, sendo maiores em agosto e setembro (Tabela 01). A evaporação e a evapotranspiração são elevadas, especialmente nos meses de primavera e verão, quando podem superar as precipitações. O armazenamento de água no solo é nulo durante o ano todo, as sim como o negativo acumulado, excedente hídrico e o índice de umidade também.

Tabela 01. Balanço hídrico mensal e anual. Município: Santa Inês. Estação: Santa Inês. Período: 1946-1976. Altitude: 481m. Latitude: 13ํㅓ'S. Longitude: 39²4'W. CAC: 50mm. Tipologia Climática: Koppen - BSh; Thornthwaite e Mather - DdB'4a' (semiárido). Fonte: INMET (1991).

\begin{tabular}{|c|c|c|c|c|c|c|c|c|}
\hline Meses & $\mathbf{T}$ & EP & $\mathbf{P}$ & P-EP & ER & DEF & \multicolumn{2}{|c|}{ Índice de } \\
\hline & $\left({ }^{\circ} \mathrm{C}\right)$ & $(\mathbf{m m})$ & $(\mathbf{m m})$ & $(\mathbf{m m})$ & $(\mathbf{m m})$ & $(\mathbf{m m})$ & Aridez & Hídrico \\
\hline Jan & 24,6 & 121,1 & 52,4 & $-68,7$ & 52,4 & 68,7 & 56,7 & $-34,0$ \\
\hline Fev & 24,8 & 110,3 & 52,6 & $-57,7$ & 52,6 & 57,7 & 52,3 & $-31,4$ \\
\hline Mar & 24,5 & 114,1 & 91,0 & $-23,1$ & 91,0 & 23,1 & 20,2 & $-12,1$ \\
\hline Abr & 23,7 & 97,8 & 71,2 & $-26,6$ & 71,2 & 26,6 & 27,2 & $-16,3$ \\
\hline Mai & 22,1 & 81,9 & 43,8 & $-38,1$ & 43,8 & 38,1 & 46,5 & $-27,9$ \\
\hline Jun & 20,9 & 69,5 & 42,5 & $-27,0$ & 42,5 & 27,0 & 38,8 & $-23,3$ \\
\hline Jul & 20,0 & 59,9 & 43,0 & $-16,9$ & 43,0 & 16,9 & 28,2 & $-16,9$ \\
\hline Ago & 20,4 & 66,8 & 26,6 & $-40,2$ & 26,6 & 40,2 & 60,2 & $-36,1$ \\
\hline Set & 21,2 & 74,3 & 18,3 & $-56,0$ & 18,3 & 56,0 & 75,4 & $-45,2$ \\
\hline Out & 22,6 & 94,2 & 42,1 & $-52,1$ & 42,1 & 52,1 & 55,3 & $-33,2$ \\
\hline Nov & 23,8 & 106,4 & 92,5 & $-13,9$ & 92,5 & 13,9 & 13,1 & $-7,8$ \\
\hline Dez & 24,1 & 116,1 & 67,6 & $-48,5$ & 67,6 & 48,5 & 41,8 & $-25,1$ \\
\hline Anual & 22,7 & 1112,5 & 643,6 & & 643,6 & 468,9 & 42,1 & $-25,3$ \\
\hline
\end{tabular}

Variação Pluviométrica de 2011

Os dados sinalizam importantes alterações na precipitação em Santa Inês no ano de 2011, em especial nos totais e nos padrões de distribuição ao longo dos meses (Figura 2). As precipitações de 2011 foram 90,5mm a menos que a série histórica, o que representa $-43,4 \%$, sendo que a diminuição 
dos totais ocorreu nos meses secos (outono-inverno). Nos meses úmidos (primavera-verão) as chuvas foram superiores às normais climatológicas, ocorrendo um importante desvio da média nos meses de fevereiro e dezembro, quando, respectivamente, as chuvas foram escassas e muito superiores à média histórica (Tabelas 02 e 03).

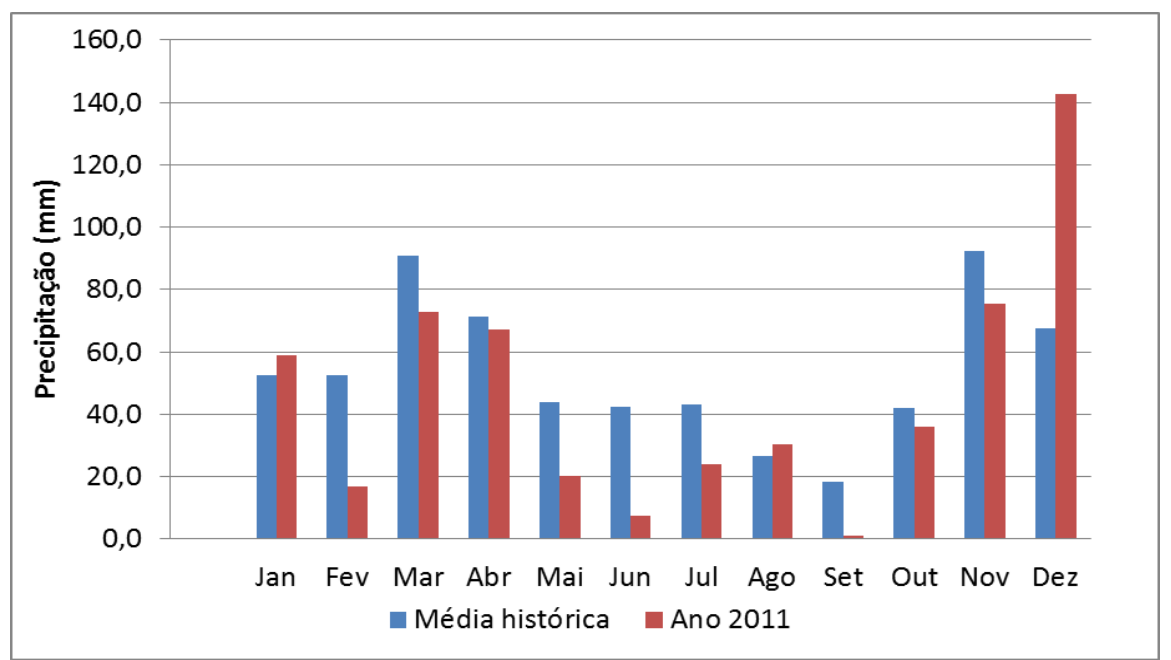

Figura 02. Relação entre as precipitações das normais climatológicas (1946-1976) e precipitações registradas no ano de 2011 em Santa Inês - Bahia. Estação: Santa Inês. Altitude: $481 \mathrm{~m}$. Latitude: $13^{0} 16$ 'S. Longitude: $39^{0} 48^{\prime} \mathrm{W}$.

Tabela 02. Relação entre as precipitações das normais climatológicas (1946-1976) e precipitações dos meses úmidos do ano de 2011 em Santa Inês - Bahia. Estação: Santa Inês. Altitude: $481 \mathrm{~m}$. Latitude: $13^{0} 16^{\prime}$ 'S. Longitude: $39^{\circ} 48^{\prime} \mathrm{W}$.

\begin{tabular}{ccccc}
\hline Meses & $\begin{array}{c}\text { Média histórica } \\
\mathbf{1 9 4 6}-\mathbf{1 9 7 6}\end{array}$ & $\begin{array}{c}\text { Ano } \\
\mathbf{2 0 1 1}\end{array}$ & $\begin{array}{c}\text { Diferença } \\
(\mathbf{m m})\end{array}$ & $\begin{array}{c}\text { Relação com a } \\
\text { média (\%) }\end{array}$ \\
\hline Nov & 92,5 & 75,5 & -17 & $-18,3$ \\
Dez & 67,6 & 142,7 & 75,1 & 111 \\
Jan & 52,4 & 59,1 & 6,7 & 12,7 \\
Fev & 52,6 & 16,8 & $-35,8$ & $-67,6$ \\
Mar & 91,0 & 73,0 & -18 & $-19,7$ \\
Abr & 71,2 & 67,1 & $-4,1$ & -6 \\
Total & 427,3 & 434,2 & 6,9 & 1,6 \\
\hline
\end{tabular}

Tabela 03. Relação entre as precipitações das normais climatológicas (1946-1976) e precipitações dos meses secos do ano de 2011 em Santa Inês - Bahia. Estação: Santa Inês. Altitude: $481 \mathrm{~m}$. Latitude: $13^{0} 16^{\prime}$ 'S. Longitude: $39^{\circ} 48^{\prime} \mathrm{W}$.

\begin{tabular}{ccccc}
\hline Meses & $\begin{array}{c}\text { Média histórica } \\
\mathbf{1 9 4 6}-\mathbf{~ 1 9 7 6}\end{array}$ & $\begin{array}{c}\text { Ano } \\
\mathbf{2 0 1 1}\end{array}$ & $\begin{array}{c}\text { Diferença } \\
(\mathbf{m m})\end{array}$ & $\begin{array}{c}\text { Relação com a } \\
\text { média }(\%)\end{array}$ \\
\hline Mai & 43,8 & 20,1 & $-23,7$ & $-54,1$ \\
Jun & 42,5 & 7,5 & -35 & $-82,3$ \\
Jul & 43,0 & 24,1 & $-18,9$ & $-43,9$ \\
Ago & 26,6 & 30,3 & 3,7 & 13,9 \\
Set & 18,3 & 1,0 & $-17,3$ & $-94,3$ \\
Out & 42,1 & 35,9 & $-6,2$ & $-14,4$ \\
Total & 216,3 & 118,9 & $-97,4$ & -45 \\
\hline
\end{tabular}

No semestre historicamente chuvoso (novembro a abril) de 2011 as precipitações acumuladas foram de 434,2mm, o que representa 1,6\% acima da média, enquanto que no semestre seco (maio a outubro) as precipitações foram de $118,9 \mathrm{~mm}$, o que representa $-45 \%$ abaixo da média. $\mathrm{O}$ maior 
desvio da média dos meses secos foi em setembro, quando as chuvas foram $-94,3 \%$, seguido de junho $(-82,3 \%)$, maio $(-54,1 \%)$ e julho $(-43,9 \%)$. No mês de janeiro de 2011 a precipitação acumulada foi superior ao esperado, $12,7 \%$ maior que a média histórica. Durante esse mês, as chuvas ficaram acima da normal climatológica em praticamente todo o nordeste brasileiro, em especial por causa da Zona de Convergência Intertropical (ZCIT), cujo posicionamento influenciou diretamente a formação de áreas de instabilidade sobre a região (INMET, 2011a).

A ZCIT esteve mais ativa no primeiro decêndio de janeiro, principalmente entre os dias 07 e 10/01 e influenciou na formação de chuvas entre os dias 05 e 09/01 em Santa Inês (Figura 03). Segundo o Boletim Agroclimatológico de janeiro de 2011 do INMET, outro sistema que influenciou diretamente as condições de tempo na região foram os Vórtices de Ciclônico em Altos Níveis da Atmosfera (VCAN). Os Vórtices de Ciclônico em Altos Níveis da Atmosfera foram observados entre os dias 05 e 07/01, 14 e 22/01 e entre os dias 27 e 30/01, influenciando na formação de chuvas em Santa Inês entre os dias 05 e 07/01, nos dias 14 e 22/01 e entre os dias 12 e 29/01 (Figura 03).

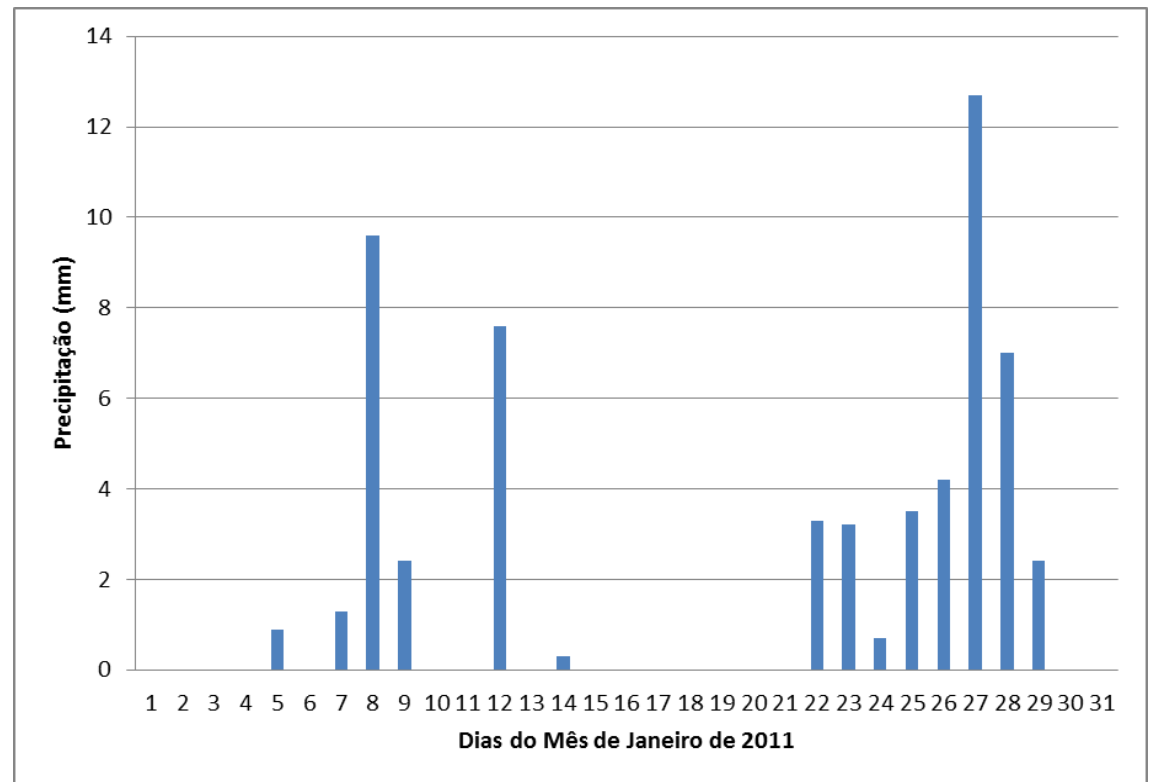

Figura 03. Precipitação nos dias de janeiro de 2011.

Durante o mês de fevereiro de 2011, as precipitações no estado da Bahia (exceto o noroeste) ficaram abaixo da média (INMET, 2011b), não obstante, Santa Inês teve um significativo desvio negativo, 67,6\% com relação à média. A Oscilação Intrassazonal de Madden e Julian (OMJ) que estava ativa no período pode ter sido desfavorável à formação de chuvas na região. Entre os meses de março a maio, a ZCIT, principal responsável pelas chuvas que ocorreram no interior do nordeste brasileiro no período (INMET, 2011c; INMET, 2011d; INMET, 2011e) atuaram em Santa Inês próximo da normalidade ou muito abaixo do esperado, o que resultou, respectivamente, em 
precipitações próximas da média histórica (março e abril) e chuvas escassas em maio (desvio negativo de 54,1\%) (Tabelas 02 e 03). Isto ocorreu, respectivamente, porque a Zona de Convergência Intertropical (ZCIT) estava posicionada a sul de sua posição climatológica e ao aquecimento anômalo das águas superficiais do Atlântico Tropical-(PROGCLIMA, 2011a).

Nos meses de junho houve um desvio negativo de 82,3\% e em julho de 43,9\% (Tabela 03), porque as anomalias positivas da TSM na região do Atlântico Norte continuaram contribuindo para a persistência de chuvas abaixo da média. Em agosto, o desvio da precipitação foi 13,9\% acima da média, provavelmente devido a resquícios de umidade advindos de áreas de instabilidade do Oceano Atlântico. Em setembro, mês historicamente mais seco, registrou apenas 1,0mm de chuva (um desvio negativo de 94,3\%) e no mês de outubro as precipitações tiveram um desvio negativo de 14,4\%. Em quase toda a região Nordeste as chuvas ficaram abaixo do esperado, por causa da atuação anômala do sistema de alta pressão do Atlântico Sul, cujo centro mais amplo posicionou-se muito próximo à costa leste do Brasil, inibindo à ocorrência de chuvas. Segundo o Boletim de Prognóstico Climático (PROGCLIMA, 2011b), sobre grande parte do continente sul-americano as anomalias positivas de radiação de onda longa refletiram uma predominante condição de estiagem.

No mês de novembro, as precipitações variaram de normal a acima da média climatológica em praticamente toda a região nordeste, por isso as precipitações em Santa Inês ficaram próximo da normalidade. Nesse mês, o INMET (20111) observou anomalias nos campos da circulação média dos ventos em médios e altos níveis da atmosfera e na posição climatológica da Alta Subtropical do Atlântico Sul (ASAS), as quais se comportaram como bloqueios atmosféricos, no sentido de inibir o avanço de outros sistemas de origem frontal que se deslocaram pelo Oceano Atlântico e reforçaram ou até mesmo intensificaram as áreas de instabilidade associadas aos sistemas frontais.

Nos eventos supracitados, o INMET observou a formação de um canal de umidade desde a região norte, passando pela região centro-oeste até a região nordeste (Bahia em especial), o qual é denominado de Zona de Convergência do Atlântico Sul (ZCAS). Como a ZCAS foram observadas no primeiro e no terceiro decêndio do mês de novembro, pode-se inferir que as chuvas da primeira quinzena do mês em Santa Inês, em especial nos dias 09 e 10 (Figura 04), tiveram como causa principal a Zona de Convergência do Atlântico Sul.

Durante o mês de dezembro de 2011, as chuvas ficaram muito abaixo da normal climatológica em praticamente todo o nordeste brasileiro (INMET, 2001m), contudo Santa Inês foi uma exceção, pois houve um desvio positivo de $75,1 \mathrm{~mm}$, o que representa $111 \%$ superior à média histórica (Tabela 02). As chuvas em Santa Inês se concentraram entre os dias 12 e 14/12, ocorrendo outro pico no dia 30/12 (Figura 5), tendo como principal causa episódios da Zona de Convergência do Atlântico Sul (ZCAS), que estiveram ativas na Bahia nesses dias. 


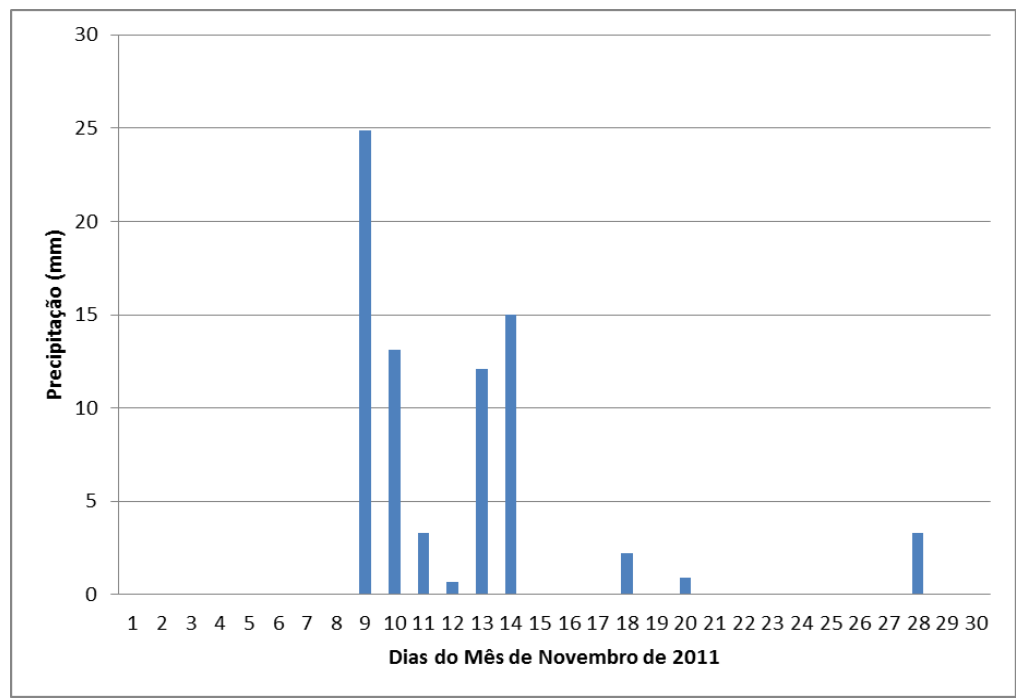

Figura 04. Precipitação nos dias de novembro de 2011.

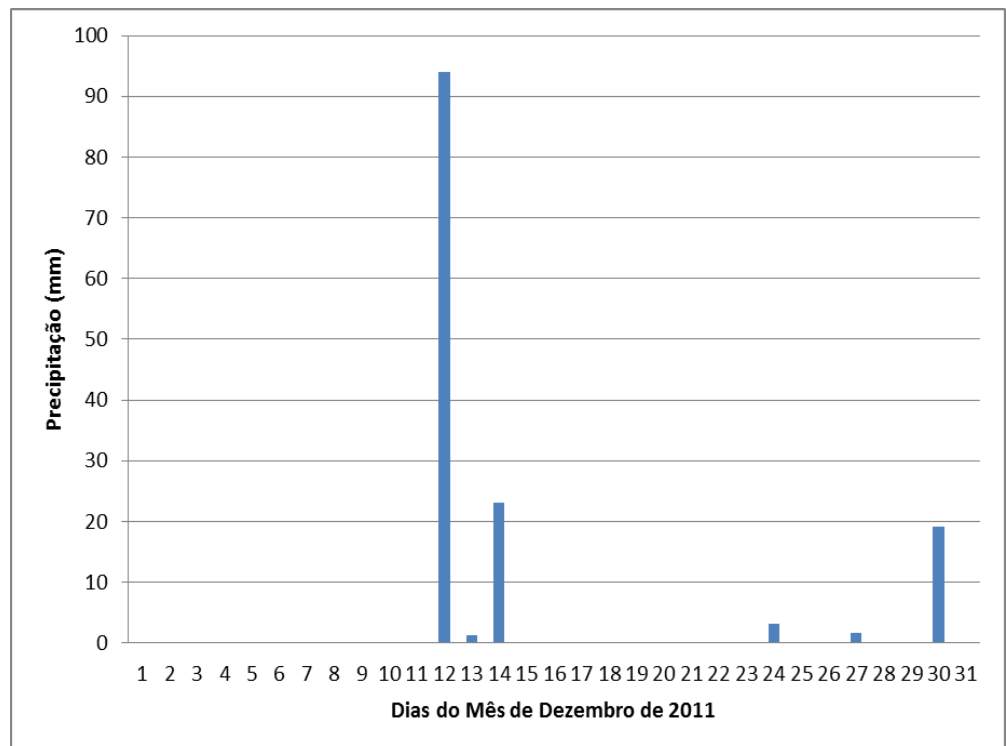

Figura 05. Precipitação nos dias de dezembro de 2011.

Variação Pluviométrica de 2012

O ano de 2012 foi mais seco que o de 2011, apresentando índices pluviométricos de regiões consideradas desérticas, ou seja, chuvas inferiores a 250mm anuais. As precipitações de 2012 foram $337,4 \mathrm{~mm}$ menores que a série histórica, o que representa um desvio negativo de 62,8\%. A diminuição dos totais ocorreu em praticamente todos os meses do ano, exceto em agosto, sendo mais expressiva no semestre historicamente considerado úmido (Figura 06).

No semestre historicamente chuvoso (novembro a abril) as precipitações acumuladas foram de 120,2mm, o que representa 71,8\% abaixo da média, enquanto que no semestre seco (maio a outubro) as precipitações foram de 118,8mm, o que representa 45\% abaixo da média (Tabelas 04 e 05). Em 2012, no período historicamente úmido, as chuvas foram escassas em todos os meses, sendo que os maiores desvios da média ocorreram em janeiro (-100\%), abril (-95,3\%), dezembro (- 
$88,3 \%)$ e março $(-70,7 \%)$, enquanto que no semestre seco o total acumulado foi similar a 2011 e o maior desvio da média ocorreu em outubro $(-71,9 \%)$, setembro $(-59,5 \%)$, junho $(-54,3 \%)$ e maio ($47,4 \%)$.

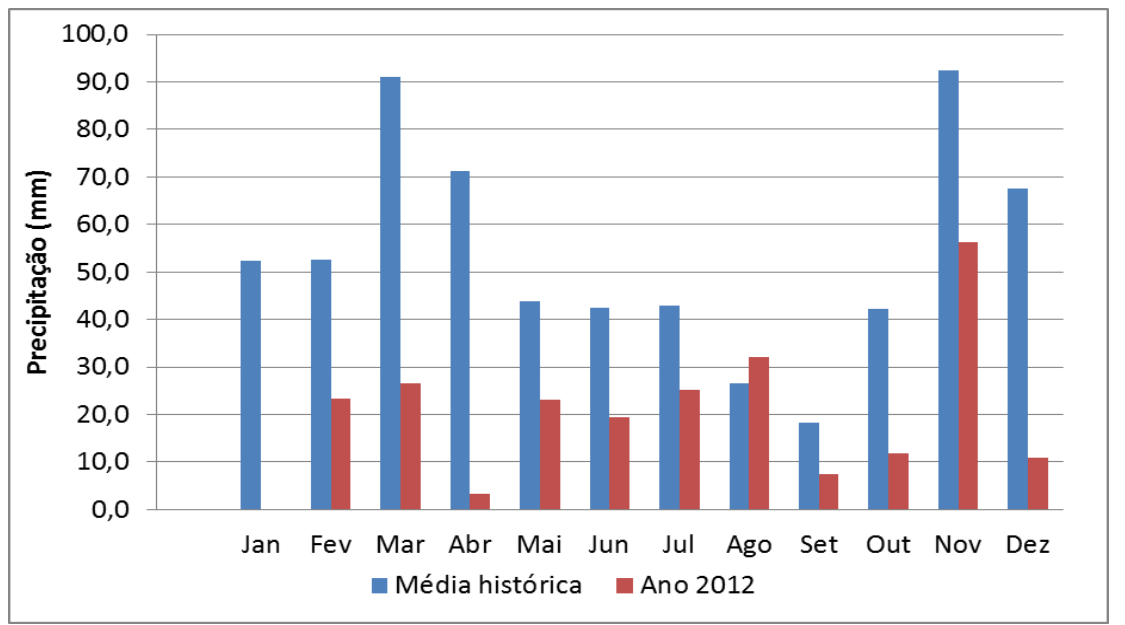

Figura 06. Relação entre as precipitações das normais climatológicas (1946-1976) e precipitações registradas no ano de 2012 em Santa Inês - Bahia. Estação: Santa Inês. Altitude: 481m. Latitude: $13^{0} 16$ 'S. Longitude: $39^{0} 48^{\prime} \mathrm{W}$.

Tabela 04. Relação entre as precipitações das normais climatológicas (1946-1976) e precipitações dos meses úmidos nos anos de 2011 e 2012 em Santa Inês - Bahia. Estação: Santa Inês. Altitude: 481m. Latitude: 13 ${ }^{0} 16^{\prime}$ S. Longitude: $39^{\circ} 48^{\prime} \mathrm{W}$.

\begin{tabular}{ccccc}
\hline Meses & Média histórica 1946-1976 & Ano 2012 & $\begin{array}{c}\text { Diferença } \\
(\mathbf{m m})\end{array}$ & $\begin{array}{c}\text { Relação com a média } \\
(\mathbf{\%})\end{array}$ \\
\hline Nov & 92,5 & 56,2 & $-36,3$ & $-39,2$ \\
Dez & 67,6 & 10,8 & $-56,4$ & $-88,3$ \\
Jan & 52,4 & 0,0 & $-52,4$ & -100 \\
Fev & 52,6 & 23,3 & $-29,3$ & $-55,1$ \\
Mar & 91,0 & 26,6 & $-64,4$ & $-70,7$ \\
Abr & 71,2 & 3,3 & $-67,9$ & $-95,3$ \\
Total & 427,3 & 120,2 & $-307,1$ & $-71,8$ \\
\hline
\end{tabular}

Tabela 05. Relação entre as precipitações das normais climatológicas (1946-1976) e precipitações dos meses secos nos anos de 2011 e 2012 em Santa Inês - Bahia. Estação: Santa Inês. Altitude: 481m. Latitude: 13 ${ }^{0} 16^{\prime}$ S. Longitude: $39^{\circ} 48^{\prime} \mathrm{W}$.

\begin{tabular}{ccccc}
\hline Meses & $\begin{array}{c}\text { Média histórica } \\
\mathbf{1 9 4 6 - 1 9 7 6}\end{array}$ & $\begin{array}{c}\text { Ano } \\
\mathbf{2 0 1 2}\end{array}$ & $\begin{array}{c}\text { Diferença } \\
(\mathbf{m m})\end{array}$ & Relação com a média (\%) \\
\hline Mai & 43,8 & 23,0 & $-20,8$ & $-47,4$ \\
Jun & 42,5 & 19,4 & $-23,1$ & $-54,3$ \\
Jul & 43,0 & 25,2 & $-17,8$ & $-41,3$ \\
Ago & 26,6 & 32,0 & 5,4 & 20,3 \\
Set & 18,3 & 7,4 & $-10,9$ & $-59,5$ \\
Out & 42,1 & 11,8 & $-30,3$ & $-71,9$ \\
Total & 216,3 & 118,8 & $-97,3$ & -45 \\
\hline
\end{tabular}

No mês de janeiro as chuvas ficaram muito abaixo da média em todas as estações meteorológicas do INMET na Bahia (INMET, 2012a) e Santa Inês acompanhou a tendência regional, não registrando precipitações. As águas superficiais mais frias que o normal no Atlântico Tropical Sul 
contribuíram para que a Zona de Convergência Intertropical (ZCIT) atuasse a norte de sua posição climatológica (INMET, 2012a; PROGCLIMA, 2012a), contribuindo para a diminuição de precipitações na área de estudo. Durante o mês de fevereiro, as precipitações no estado da Bahia continuaram muito abaixo da média e em Santa Inês o desvio negativo foi de 55,1\%. A Zona de Convergência Intertropical (ZCIT) continuou atuando a norte de sua posição climatológica, as condições de bloqueio no escoamento atmosférico nos oceanos Pacífico e Atlântico Sul e o sinal desfavorável da Oscilação Madden-Julian (OMJ) (INMET, 2012b; PROGCLIMA, 2012b) foram fatores que contribuíram para a escassez de chuvas na região.

Em março, houve um desvio negativo de 70,7\% das chuvas em Santa Inês, representando a tendência de precipitações abaixo da média no estado da Bahia, com exceção de seu extremo sul. Além da inexpressiva atuação da Zona de Convergência Intertropical (ZCIT) e dos Vórtices Ciclônicos de Altos Níveis (VCAN) na Bahia, principais responsáveis pela formação das áreas de instabilidade no nordeste nesse mês, a presença de uma massa de ar seco no interior do estado inibiu a ocorrência de chuvas (INMET, 2012c). Até o dia 11 de março, 75 municípios da Bahia haviam decretado situação de emergência.

Em abril, as precipitações no estado da Bahia continuaram abaixo da média, exceto o seu extremo sul, e em Santa Inês houve um desvio negativo de 95,3\% das chuvas. Segundo o Boletim Agrometeorológico do INMET (2012d), as águas superficiais mais frias do que o normal no Oceano Atlântico Sul, próximo a costa da região Nordeste, não favoreceram a atuação da Zona de Convergência Intertropical (ZCIT), o sistema meteorológico mais importante na ocorrência de uma estação chuvosa regular no semiárido nordestino.

Ainda segundo o Boletim Agrometeorológico do INMET (2012d), durante os meses de fevereiro, março e abril a ZCIT não esteve posicionada de modo favorável a contribuir para a formação de áreas de instabilidade e, consequentemente, a ocorrência de chuvas, especialmente no sertão nordestino. As oscilações intrassazonais continuaram bem marcadas nos oceanos Índico e Pacífico e também contribuíram para a diminuição das chuvas, em particular no Nordeste do Brasil, durante a primeira quinzena de abril (PROGCLIMA, 2012c).

De acordo com o INMET (2012d), em abril a ocorrência de chuvas abaixo da média climatológica na maior parte Brasil foi associada principalmente ao padrão de águas superficiais mais frias que o normal na região do Atlântico Tropical, que intensifica o sistema de alta pressão atmosférica sobre o oceano e áreas continentais adjacentes, desfavorecendo a formação de nuvens e precipitação. O mês de maio representa o início do período seco em praticamente todo semiárido nordestino e, por isso, era de se esperar precipitações escassas em Santa Inês. Contudo, as chuvas tiveram um desvio negativo de $47,4 \%$ na cidade, o qual foi provocado por uma intensa massa de ar 
quente e seca que predominou sobre praticamente todo o semiárido, inibindo a formação de áreas de instabilidade (INMET, 2012e).

Nos meses de junho e julho as precipitações foram abaixo da média, um desvio negativo de $54,3 \%$ e 41,3\%, respectivamente. Esses meses historicamente são secos, contudo os volumes abaixo da média podem refletir a atuação de uma massa de ar seco. Em agosto as precipitações ficaram próximas da normalidade, contudo foram superiores à média histórica.

No mês de outubro, as chuvas ainda são fracas e irregulares na região nordeste, contudo em Santa Inês ficaram muito abaixo da média histórica, um desvio negativo de 71,9\%, provavelmente por causa da massa de ar quente e seca $(\mathrm{mTc})$ que atuou sobre o semiárido em praticamente todo o mês. Além disso, o aquecimento anômalo das águas superficiais do Atlântico Norte e o resfriamento anômalo do Atlântico Sul devem ter contribuído (PROGCLIMA, 2012d).

Em novembro, as precipitações em Santa Inês ficaram muito abaixo da média histórica, um desvio negativo de 39,2\% e em dezembro as chuvas foram ainda mais escassas, provavelmente porque a ZCIT estava posicionada ao norte de sua posição climatológica (INMET, 20121). Segundo o INMET (20121), não houve registro de chuva em grande parte da região Nordeste.

\section{CONSIDERAÇÕES FINAIS}

Os sistemas meteorológicos de meso e grandes escalas são responsáveis pelas precipitações e sua escassez no semiárido brasileiro e em Santa Inês não foge à regra. $\mathrm{O}$ entendimento desses sistemas e o seu monitoramento são fundamentais para os gestores públicos e a população em geral, em especial para gerar alertas precoces individuais, coletivos e orientar ações que oportunizem uma melhor convivência com a seca.

Embora a fase fria do fenômeno Enos-Oscilação Sul estivesse ativa em vários dos meses analisados, fenômenos oceano-atmosféricos, como as águas superficiais mais frias que o normal no Atlântico Tropical Sul, as condições de bloqueio no escoamento atmosférico nos oceanos Pacífico e Atlântico Sul e o sinal desfavorável da Oscilação Madden-Julian (OMJ) foram fatores que contribuíram para a escassez de chuvas no semiárido nordestino. Em Santa Inês, o desvio negativo, ocorreu nos meses secos, o que agravou os problemas relacionados à seca. O ano de 2012 foi mais seco que o de 2011, apresentando índices pluviométricos de regiões consideradas desérticas. As precipitações de 2012 apresentaram um desvio negativo de 337,4mm e a diminuição dos totais ocorreu em praticamente todos os meses do ano, exceto em agosto. 


\section{AGRADECIMENTOS}

A Amanda Alcântara Sampaio e Carolina Moreira dos Anjos pelo apoio de campo no desenvolvimento do trabalho e ao Instituto Federal Baiano por ter financiado o projeto através do Edital de Pró-Extensão 2012/2013 da Pró-reitoria de Extensão.

\section{REFERÊNCIAS}

INGÁ/CEMBA. Disponível em: http://www.srh.ba.gov.br. Acesso em: 05/12/2009.

Instituto Nacional de Meteorologia - INMET. Boletim Agroclimatológico Mensal. Janeiro de 2011a. Disponível em: http://www.inmet.gov.br. Acesso em: 10/07/2012.

Instituto Nacional de Meteorologia - INMET. Boletim Agroclimatológico Mensal. Fevereiro de 2011b. Disponível em: http://www.inmet.gov.br. Acesso em: 10/07/2012.

Instituto Nacional de Meteorologia - INMET. Boletim Agroclimatológico Mensal. Março de 2011c. Disponível em: http://www.inmet.gov.br. Acesso em: 10/07/2012.

Instituto Nacional de Meteorologia - INMET. Boletim Agroclimatológico Mensal. Abril de 2011d. Disponível em: http://www.inmet.gov.br. Acesso em: 10/07/2012.

Instituto Nacional de Meteorologia - INMET. Boletim Agroclimatológico Mensal. Maio de 2011e. Disponível em: http://www.inmet.gov.br. Acesso em: 10/07/2012.

Instituto Nacional de Meteorologia - INMET. Boletim Agroclimatológico Mensal. Junho de 2011f. Disponível em: http://www.inmet.gov.br. Acesso em: 10/07/2012.

Instituto Nacional de Meteorologia - INMET. Boletim Agroclimatológico Mensal. Julho de 2011g. Disponível em: http://www.inmet.gov.br. Acesso em: 10/07/2012.

Instituto Nacional de Meteorologia - INMET. Boletim Agroclimatológico Mensal. Agosto de 2011h. Disponível em: http://www.inmet.gov.br. Acesso em: 10/07/2012.

Instituto Nacional de Meteorologia - INMET. Boletim Agroclimatológico Mensal. Setembro de 2011i. Disponível em: http://www.inmet.gov.br. Acesso em: 11/07/2012.

Instituto Nacional de Meteorologia - INMET. Boletim Agroclimatológico Mensal. Outubro de 2011j. Disponível em: http://www.inmet.gov.br. Acesso em: 11/07/2012.

Instituto Nacional de Meteorologia - INMET. Boletim Agroclimatológico Mensal. Novembro de 20111. Disponível em: http://www.inmet.gov.br. Acesso em: 11/07/2012.

Instituto Nacional de Meteorologia - INMET. Boletim Agroclimatológico Mensal. Dezembro de $2011 \mathrm{~m}$. Disponível em: http://www.inmet.gov.br. Acesso em: 11/07/2012.

Instituto Nacional de Meteorologia - INMET. Boletim Agroclimatológico Mensal. Janeiro de 2012a. Disponível em: http://www.inmet.gov.br. Acesso em: 22/02/2012. 
Instituto Nacional de Meteorologia - INMET. Boletim Agroclimatológico Mensal. Fevereiro de 2012b. Disponível em: http://www.inmet.gov.br. Acesso em: 15/03/2012.

Instituto Nacional de Meteorologia - INMET. Boletim Agroclimatológico Mensal. Março de 2012c. Disponível em: http://www.inmet.gov.br. Acesso em: 20/04/2012.

Instituto Nacional de Meteorologia - INMET. Boletim Agroclimatológico Mensal. Abril de 2012d. Disponível em: http://www.inmet.gov.br. Acesso em: 18/05/2012.

Instituto Nacional de Meteorologia - INMET. Boletim Agroclimatológico Mensal. Maio de 2012e. Disponível em: http://www.inmet.gov.br. Acesso em: 15/06/2012.

Instituto Nacional de Meteorologia - INMET. Boletim Agroclimatológico Mensal. Junho de 2012f. Disponível em: http://www.inmet.gov.br. Acesso em: 20/07/2012.

Instituto Nacional de Meteorologia - INMET. Boletim Agroclimatológico Mensal. Julho de 2012g. Disponível em: http://www.inmet.gov.br. Acesso em: 13/08/2012.

Instituto Nacional de Meteorologia - INMET. Boletim Agroclimatológico Mensal. Agosto de 2012h. Disponível em: http://www.inmet.gov.br. Acesso em: 21/09/2012.

Instituto Nacional de Meteorologia - INMET. Boletim Agroclimatológico Mensal. Setembro de 2012i. Disponível em: http://www.inmet.gov.br. Acesso em: 15/09/2012.

Instituto Nacional de Meteorologia - INMET. Boletim Agroclimatológico Mensal. Outubro de 2012j. Disponível em: http://www.inmet.gov.br. Acesso em: 15/11/2012.

Instituto Nacional de Meteorologia - INMET. Boletim Agroclimatológico Mensal. Novembro de 20121. Disponível em: http://www.inmet.gov.br. Acesso em: 12/12/2012.

Instituto Nacional de Meteorologia - INMET. Boletim Agroclimatológico Mensal. Dezembro de 2012m. Disponível em: http://www.inmet.gov.br Acesso em: 18/01/2013.

MANTUA, N. J., S.R. HARE, Y. ZHANG, J. M. WALLACE, and R. C. FRANCIS. A Pacific interdecadal climate oscillation with impacts on salmon production. Bulletin of the American Meteorological Society, 78, pp. 1069-1079. 1997.

PROGCLIMA. Boletim de Prognóstico Climático. MCT/INPE/CPTEC-INMET. Ano 08, Número 05, 2011a. Acesso em: 15/02/2012.

PROGCLIMA. Boletim de Prognóstico Climático. MCT/INPE/CPTEC-INMET. Ano 08, Número 10, 2011b. Acesso em: 15/02/2012.

PROGCLIMA. Boletim de Prognóstico Climático. MCT/INPE/CPTEC-INMET. Ano 09, Número 01, 2012a. Acesso em: 20/01/2013.

PROGCLIMA. Boletim de Prognóstico Climático. MCT/INPE/CPTEC-INMET. Ano 09, Número 02, 2012b. Acesso em: 20/01/2013. 
PROGCLIMA. Boletim de Prognóstico Climático. MCT/INPE/CPTEC-INMET. Ano 09, Número 04, 2012c. Acesso em: 20/01/2013.

PROGCLIMA. Boletim de Prognóstico Climático. MCT/INPE/CPTEC-INMET. Ano 09, Número 10, 2012d. Acesso em: 20/01/2013.

SORRE, M. Le climat. In: Les fondements de la géographie humaine. Paris: Armand Colin, 1951.

Recebido em: 14/08/2016

Aceito para publicação em: 14/08/2016 